\title{
Persons with acquired brain injury: a disabled diaspora
}

\author{
Conor O'Neill, Mark Delargy, Clare Mclnerney
}

\section{Ir J Psych Med 2008; 25(2): 38-39}

The Vision for Change Document states that "Neuropsychiatry service needs are largely unmet in Ireland and where they are met, it is by existing liaison psychiatry mental health services. Additional expertise and treatment is purchased from abroad but should and can be provided here".

Acquired Brain Injury ( $\mathrm{ABI}$ ) prevalence rates of up to $2 \%$ have been described in the US. ${ }^{2}$ In Ireland, Vision for Change estimated a neuropsychiatry need in $\mathrm{ABl}$ of approximately 80 cases per 100,000 population annually. ${ }^{1}$ The risk of $A B I$ is greatest between the mid-teen years and mid-twenties, and again in the elderly, with males at particular risk. The commonest causes are transport-related injuries, followed by falls which are more frequent in older age groups. ${ }^{3}$ Residual deficits in cases of mild, moderate and severe $A B I$ have been estimated at $10 \%, 67 \%$ and $100 \%$ respectively. ${ }^{4}$

Psychiatric sequelae are common and may develop several years after the initial injury. A 30 year follow-up study of 60 $A B I$ patients found a lifetime prevalence of $26.7 \%$ for DSMIV major depression. ${ }^{5}$ Kreutzer et al found a prevalence rate for DSM-IV major depression of $42 \%$ at 2.5 years post-injury. ${ }^{6}$ Anatomical regions implicated in the aetiology of psychosis, such as the temporal lobes, prefrontal cortex and hippocampus, are particularly vulnerable to acquired injury, and $A B I$ has been estimated to account for $1-17 \%$ of all cases of schizophrenia. $^{7}$

Certain subgroups of people with major mental illness are known to be overrepresented in prison populations. In the remand setting, the disproportionate accumulation of persons with psychotic illness has already been reported. ${ }^{\theta} \mathrm{A}$ recent comprehensive survey of the Irish prison population found prevalence rates of $7.2 \%$ with lifetime history of $A B I$ among sentenced prisoners. ${ }^{\circ} \mathrm{A}$ population of remand prisoners with $\mathrm{AB}$ land learning disabilities also exists, often charged with relatively trivial offences, and vulnerable in the prison setting. These patients are generally male, relatively young and often homeless. Such prisoners may have difficulties in meeting bail requirements and can spend unusually long periods on remand due to difficulties locating appropriate treatment and placement facilities. This is particularly the case where supported accommodation or placement in specialist inpatient centres is required. The accumulation of these individuals in the Criminal Justice System may reflect the

*Conor O'Neill, Consultant Forensic Psychiatrist, Central Mental Hospital, Dundrum, Dublin 14, Ireland

Mark Delargy, Consultant in Rehabilitation Medicine, National

Rehabilitation Hospital, Dun Laoghaire, Co Dublin, Ireland

Clare Mclnerney, Senior Registrar, Central Mental Hospital, Dundrum, Dublin 14, Ireland.

*Correspondence

SUBMITTED: 19 FEBRUARY 2008. ACCEPTED: 30 APRIL, 2008. inability of overstretched services elsewhere in the system to meet existing need.

A number of agencies exist in the community to provide support and assistance to people with $A B I-r e l a t e d$ difficulties. BRI (The Acquired Brain Injury Advocacy Association) strives to ensure that all those affected by an acquired brain injury have the best possible quality of life, and works to achieve this by prevention, increasing public awareness and promoting joined-up services for those with ABI. Headway Ireland has offices in Dublin, Cork, Kerry and Limerick, as well as an information centre in the south east, and provides individual and group day services, psychological (including neuropsychological) services and rehabilitation programmes. The Peter Bradley Foundation provides assessments, assisted living, community rehabilitation and case management services. It also offers information and support to families of people with acquired brain injuries. The National Rehabilitation Hospital has a neuro-behavioural clinic and inpatient services providing multidisciplinary input from rehabneuropsychology, neuropsychiatry and other services.

While the majority of persons living with $\mathrm{ABI}$-related disabilities function well and lead rewarding lives in the community, a proportion require additional supports. Individuals suffering from complications of $A B I$ may have complex needs, often beyond the skills and service remit of general adult mental health services. ${ }^{6}$ In particular many services have limited access to neuropsychological assessment. Advocacy networks emphasise the difficulties experienced by some people with such difficulties in accessing appropriate mental health services.

Difficulties in accessing mental health care and appropriate accommodation may be further exacerbated by homelessness. Pre-morbid $\mathrm{ABI}$ is particularly common amongst homeless populations. A New York study found $40 \%$ of homeless individuals with a schizophrenia-like psychosis had a history of $\mathrm{ABI} .^{10}$

Supported residential facilities are required where individuals are unable to live independently. Some will require such placements as part of a step-down process from inpatient units, while others will require longer-term rehabilitation. Standard psychiatric community hostels typically struggle to meet the needs of persons with $\mathrm{ABI}$ and comorbid psychiatric illness. While agencies such as the Peter Bradley foundation provide a limited number of residential placements (approximately 50), these are insufficient in number and may have difficulty in addressing the needs of individuals exhibiting more markedly challenging behaviour. Independent-sector agencies have developed supported community residences to meet this need. Such facilities provide $\mathbf{2 4}$ hour support and rehabilitation for persons with $\mathrm{ABI}$.

Challenging behaviour is not uncommon among persons 
with $A B I$, although serious violence is rare. Behavioural treatments can be highly effective in the management of aggressive behaviour in such individuals. The National Rehabilitation Unit, among its 46 beds allocated to ABI, provides a nine-bedded inpatient rehabilitation unit for persons with behavioural difficulties after $A B I$. Access to specialised inpatient units with specific skills in the behavioural management of severe challenging behaviour is extremely limited in Ireland, although one such unit has recently been opened in the independent sector. When made available on an individual basis such services have typically been purchased in the United Kingdom, in units that also accommodate Irish Learning Disabled patients with challenging behaviour. The annual cost of such a placement is in the order of several hundred thousand euros per patient. Clearly it is less than ideal that such individuals should spend extended periods geographically separated from family and friends. Eventual return to Ireland remains difficult due to the shortage of appropriate long-term residential facilities for people with persistent challenging behaviour after ABI. The number of this "disabled diaspora", while unknown, is such that there is a clear economic argument for the development in Ireland of specialised challenging behaviour units skilled in the behavioural management and rehabilitation of persons with $\mathrm{ABI}$.

Vision for Change recommended the development of neuropsychiatric multidisciplinary teams and recognised the need for a challenging behaviour unit in Ireland. It is apparent that these recommendations need to be implemented as a matter of urgency. In planning any such service, account must be taken of numbers already occupying such facilities abroad in addition to the existing need in Ireland. Planning must also incorporate the need for step-down facilities and longer-term supported accommodation in the community as well as supports for the majority who live independently with family support in the community.

Placement in forensic psychiatric settings is rarely indicated and it is important that prisons and forensic psychiatric and rehabilitation hospitals do not become proxies for services currently unavailable in Ireland. There is a need for close integration between mental health service providers, service users, forensic services, rehabilitation medicine and other agencies, to meet the complex needs of those with acquired brain injuries.

\section{References}

1. A Vision for Change. Report of the Expert Group on Mental Health Policy. CSO Dublin: 157-159, 2006.

2. Thurman DJ, Alverson C. Browne D, et al: Acquired Brain Injury in the United States: A Report to Congress. Centers for Disease Control and Prevention, 1999.

3. Kraus JF, Chu LD. Epidemiology of Acquired Brain Injury. In; Silver JM, McAllister TW Yudofsky SC, eds. Textbook of Acquired Brain Injury. Washington DC: American Psychiatric Publishing, 2005: 8-13.

4. Torner J, Schootman M. Epidemiology of closed head injury. In: Rizzo M, Tranel D, eds. Head Injury and Postconcussive Syndrome. New York: Churchill Livingstone, 1996: 19-46.

5. Koponen S, Taiminen T, Portin R et at: Axis I and II Psychiatric Disorders after Acquired Brain Injury: a 30 year follow-up study. Am J Psychiatry 2002; 159: 1315 1321.

6. Kreutzer JS, Seel RT, Gourley E: The prevalence and symptom rates of depression after Acquired Brain Injury: a comprehensive examination. Brain Inj 2001;15: 563-576, 7. Corcoran CM, Malaspina D. Acquired Brain Injury and schizophrenia risk. Int J Ment 7. Corcoran 2001 ; $30:$ 17-32,

8. Linehan SA, Duffy DM, Wright B, Curtin K, Monks S, Kennedy HG. Psychiatric morbidity in a cross-sectional sample of male remanded prisoners. Irish Journal of Psychological Medicine 2005; 22 (4): 128-132.

9. Duffy D, Linehan S, Kennedy HG. Psychiatric morbidity in the male sentenced Irish prisons population. Irish Journal of Psychological Medicine 2006; 23(2): 47-53.

10. Silver MA, McKinnon K: Characteristics of homeless placements discharged from an intensive placement unit. Hosp Community Psychiatry 1993; 44: 576-578.

Declaration of Interest: None. 


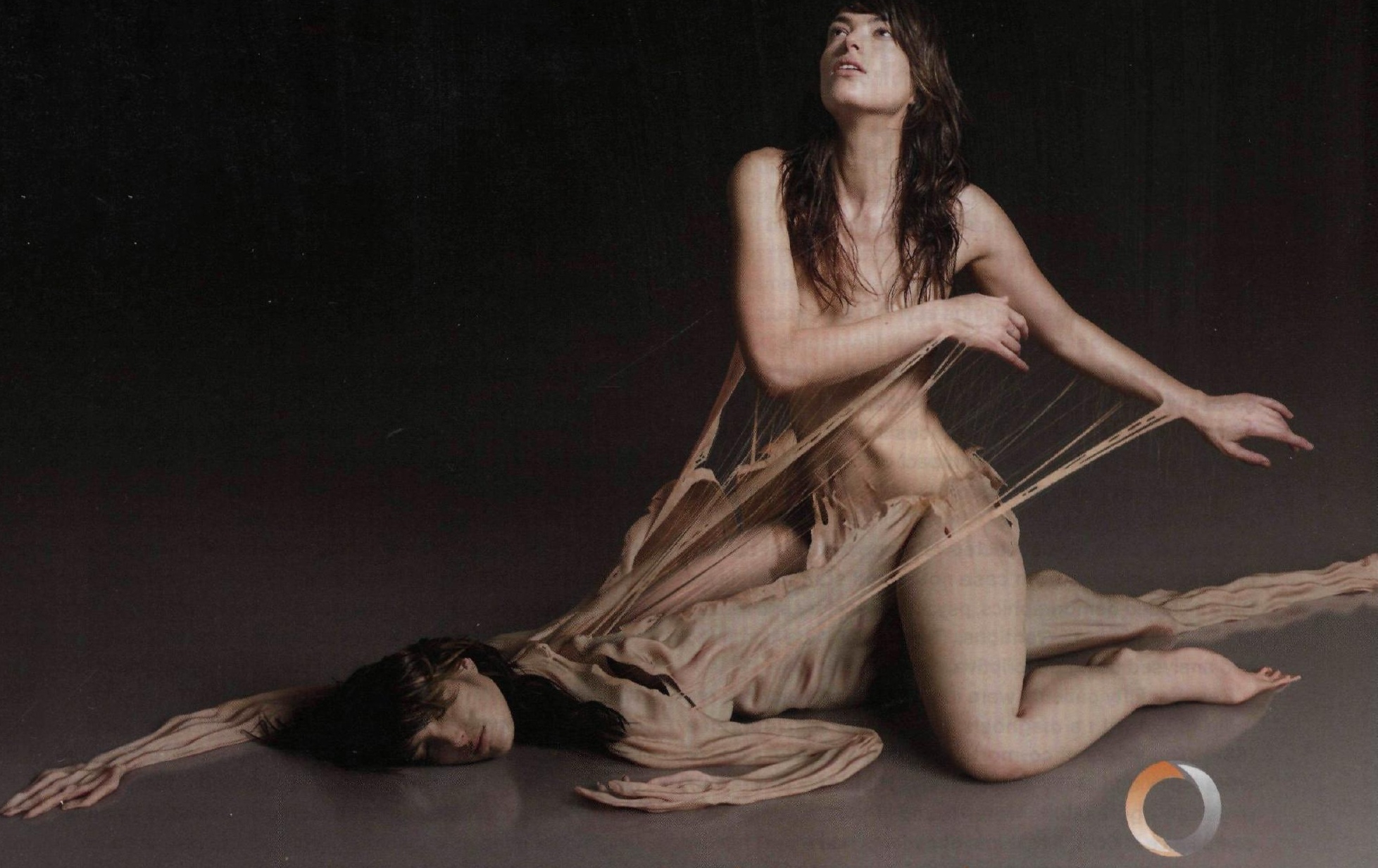

For the person within

Invega ${ }^{\circledR}$ is a new atypical antipsychotic for the treatment of schizophrenia.'

Invega ${ }^{\circledR}$ is efficacious across all PANSS scores ${ }^{2}$ with overall incidence of common side-effects similar to placebo at the recommended dose of $6 \mathrm{mg}^{3}{ }^{3}$

\section{PALIPERIDONE Prolonged-Release Tablets}

\section{JANSSEN-CILAG}

INVEGA PRESCRIBING INFORMATION INVEGA® PROLONCED RELEASE TABLETS ( $3 \mathrm{mg}, 6 \mathrm{mg}$ and $9 \mathrm{mg}$ ) ACTIVE INGREDIENT: $3 \mathrm{mg}, 6 \mathrm{mg}$ or $9 \mathrm{mg}$ paliperidone. Please refer to Summary of Product Characteristics (SMPC) before prescribing. INDICATION: INVEGA (paliperidone) is indicated for the treatment of schizophrenia. DOSAGE \& ADMINISTRATION: Adults: recommended dose is $6 \mathrm{mg}$ once daily in the morning with or without food (do not alternate). Initial dose titration not required. Dose may be adjusted within recommended range $(3 \mathrm{mg}$ to $12 \mathrm{mg}$ once daily) after clinical reassessment. Swallow tablets whole with liquid. Children and adolescents: Not recommended. Elderly: Caution in elderly dementia patients with stroke risk factors. Renal impairment: $3 \mathrm{mg}$ initial dose recommended in patients with mild to moderate renal impairment. $3 \mathrm{mg}$ every other day recommended initial dose in severe renal impairment. Do not use in patients with creatinine clearance below $10 \mathrm{ml} / \mathrm{min}$. Hepatic impairment: No dose adjustment for mild or moderate hepatic impairment. Caution in severe hepatic impairment. CONTRAINDICATIONS: Hypersensitivity to paliperidone, risperidone, or excipients. SPECIAL WARNINGS \& PRECAUTIONS: Cardiovascular disease: Caution in patients with known cardiovascular disease, or family history of Q-T prolongation. INVEGA may induce orthostatic hypotension in some patients. Use with caution in cerebrovascular disease and conditions that predispose to hypotension. Neuroleptic Malignant Syndrome: Discontinue INVEGA if symptoms/signs develop. Tardive dyskinesia: If signs/symptoms appear, consider discontinuing all antipsychotics, including INVEGA. Patients with diabetes mellitus/hyperglycaemia: Appropriate clinical monitoring is advisable (rare increases in blood glucose have been reported). Patients with seizures: Caution where there is a history of seizures/other conditions that potentially lower the seizure threshold. Patients with dysphagia: Do not administer to patients with significant swallowing difficulty or known gastro-intestinal strictures. Patients with decreased gastro-intestinal transit time: Reduced absorption of paliperidone may result. Patients with renal impairment: See Dosage. Do not use in patients with creatinine clearance below $10 \mathrm{ml} / \mathrm{min}$. Patients with hepatic impairment: See Dosage. Caution in severe hepatic impairment. Elderly patients with dementia: Use with caution in elderly dementia patients with risk factors for stroke. Priapism: no cases reported in clinical trials with INVEGA: paliperidone may be associated with this risk due to its alpha-adrenergic blocking effects. Body temperature regulation: Care when prescribing to patients experiencing conditions which may contribute to core body temperature elevation. Anti-emetic effect: Observed in paliperidone preclinical studies; if occurs in human patients may mask signs and symptoms of overdosage with certain medicines, or of medical conditions such as intestinal obstruction, Reye's syndrome, brain tumour etc. Lactose content ( $3 \mathrm{mg}$ tablets only): Avoid in patients with rare hereditary galactose intolerance, Lapp lactase deficiency or glucosegalactose malabsorption. SIDE EFFECTS: The most frequently reported ADRs in INVEGA treated subjects in clinical trials were: Headache, tachycardia, akathisia, sinus tachycardia, extrapyramidal disorder, somnolence, dizziness, sedation, tremor, hypertonia, dystonia, orthostatic hypotension, dry mouth. Uncommon: Anaphylactic reaction, increased appetite, nightmare, dizziness (postural), dyskinesia, Grand mal convulsion, syncope, oculegyration, palpitations, sinus arrhythmia, hypotension, ischaemia, muscle rigidity, amenorrhoea, breast discharge erectile dysfunction, galactorrhoea, gynaecomastia, irregular menstruation, oedema. Extrapyramidal Symptoms (EPS): No difference observed between placebo and the $3 \mathrm{mg}$ and $5 \mathrm{mg}$ doses of INVECA. Dose-relatedness for EPS was seen with higher INVECA doses $(9 \mathrm{mg}$ and $12 \mathrm{mg}$ ). Laboratory Tests:-Serum Prolactin: median increases observed in $67 \%$ of subjects in clinical trials with INVECA. however potentially prolactin-related adverse of subjects in clinical trials with INVEGA: however potentially prolactin-related adverse events were reported in $2 \%$ subjects overall. Weight gain: clinical trials revealed similar incidence of weight gain for INVECA $3 \mathrm{mg}$ and 6 mg compared with placebo; higher incidence rrhythmias, sudden unexplained cieath, cardiac arrest and Torsade de pointes may occur with antipsychotics. Refer to $5 \mathrm{mPC}$ for other side effects. PREGNANCY: INVEGA should not be used during pregnancy. LACTATION: INVECA should not be used while breastfeeding. INTERACTIONS: Caution prescribing INVEGA with medicines that prolong QT interval e.g. class IA and class III antiarrhythmics some antihistaminics, some other antipsychotics. some antimalarials. Potential for INVEGA to affect other medicines: Not expected to cause clinically important pharmacokinetic interactions with medicines metabolized by cytochrome P. 450 isozymes. Use with caution in conjunction with: centrally acting medicines e.g. anxiolytics, antipsychotics, hypnotics, opiates, or alcohol; medicines known to lower seizure threshold i.e. phenothiazines, butyrophenones, tricyclics, SSRIs, tramadol, mefloquine etc: medicines capable of inducing orthostatic hypotension (an additive effect may be observed when INVECA is co-administered) levodopa and other dopamine agonists (paliperidone may must be prescribed affect INVEGA: No indications from in vitro and in vivo studies that isozymes CYP2D6 and CYP3A4 are significant in the metabolism of paliperidone. Concomitant administration of INVECA and paroxetine (a potent CYP2D 6 inhibitor) showed no clinically significant effect on paliperidone pharmacokinetics. Metoclopramide and other medicines affecting C.I. transit time may aiter paliperidone absorption. Do not use INVEGA with oral risperidone as additive paliperidone exposure may occur.LEGAL CATEGORY: Prescription Only Medicine PRESENTATIONS, PACK SIZES \& PRODUCT LICENCE NUMBERS: $3 \mathrm{mg}, 6 \mathrm{mg}, 9 \mathrm{mg}$ prolonged release tablets. EU/1/07/395/001,1/07/395/006 and 1/07/395/011. Blister packs of 28 tablets. MARKETING AUTHORISATION HOLDER: JANSSEN-CILAG INTERNATIONAL NV, Turnhoutseweg 30, B-2340 Beerse, Belgium. FURTHER INFORMATION IS AVAILABLE FROM: Janssen-Cilag Ltd, Saunderton, High Wycombe, Buckinghamshire HP14 4HJ UK. (c) Janssen-Cilag Ltd 2007. PIVER240707.

References. 1. Summary of Product Characteristics. Invega ER. June 2007. 2. Kramer M et al Poster P.3.a.039. Presented at ECNP 2006; Paris, France, 16-20 September 2006. 3. Meltzer Het al. Poster 2007. Presented at ICOSR 2007, 28th March-15t April 2007, Colorado, USA. Date of preparation: September 2007. IRE/IBE/0026/2007 